\title{
ДИАЛЕКТИКА (ЛОГИКА) «КАПИТАЛА» К. МАРКСА: К ВОПРОСАМ ТРАКТОВКИ"
}

\author{
(c) 2018 Сычев Николай Васильевич \\ доктор экономическихнаук, профессор \\ Институт экономики РАН \\ 117218, Москва, Нахимовский проспект, 32 \\ E-mail: niks.52@mail.ru
}

Внимание акцентируется на необходимости создания систематического труда по диалектике (логике) «Капитала» К. Маркса, имеющего ключевое значение для развития не только философии, но и политической экономии. Анализируются концептуальные идеи, выдвинутые советскими философами в рамках двух главных направлений, ориентированных на решение поставленной проблемы, присущие им достоинства и недостатки. Раскрываются две основные причины, не позволившие создать данный труд. Выделяются три весьма важных обстоятельства, касающиеся определения исходной категории социалистической экономики. Излагается авторская точка зрения по рассматриваемым вопросам.

Ключевые слова: «Капитал» К. Маркса, диалектический метод, диалектика, логика, экономические категории, объективная логика, субъективная логика, конкретное, абстрактное, философия, политическая экономия, производительные силы, производственные отношения, экономическая система.

Как известно, «Капитал» К. Маркса - единственное крупное произведение, в котором впервые сознательно применен диалектический метод в одной общественной науке - политической экономии. Такое применение послужило отправным пунктом критики прежних представлений о предмете и методе политэкономии и превращении ее в подлинную науку. Оно стало возможным благодаря коренной переработке и критическому переосмыслению «рационального зерна» идеалистической диалектики Г. Гегеля с точки зрения материализма, органического синтеза последнего с диалектикой и выработки на этой основе материалистической диалектики как метода научного познания. В этой связи Ф. Энгельс писал: «Выработку метода (диалектического.- Н.С.), который лежит в основе марксовой критики политической экономии, мы считаем результатом, который по своему значению едва ли уступает основному материалистическому воззрению» $(1,13$, с. 497$)$.

Заметим, К. Маркс придавал этому вопросу столь большое значение, что намеревался написать специальную работу по диалектике. Именно об этом свидетельствует его письмо к Ф. Энгельсу от 14 января 1858 г., в котором он указывал: «Для метода обработки материала (здесь имеются в виду экономические рукописи.- Н.С.) большую услугу оказало мне то, что я по чистой случайности вновь перелистал «Логику» Гегеля. Если когда-нибудь нашлось время для таких работ, я с большим удовольствием изложил бы на двух или трех печатных листах в доступной здравому человеческому рассудку форме то $p a-$ циональное, что есть в методе, который Гегель открыл, но в то же время мистифицировал» (2, 29, с. 212). Спустя десять лет К. Маркс писал И. Дицгену: «Когда я сброшу экономическое бремя (здесь имеется в виду работа над «Капиталом».Н.С.), я напишу «Диалектику». Истинные законы диалектики имеются уже у Гегеля - правда в мистической форме. Необходимо освободить их от этой формы» ... (3, 32, с. 456).

К сожалению, К. Марксу так и не удалось реализовать свое намерение (этот вопрос нуждается в особом рассмотрении). Но в его трудах содержатся многочисленные высказывания, которые могут служить примером сознательного применения диалектического метода к исследованию социально-экономических явлений. Разумеется, исключительно важное методологическое значение здесь имеет главный труд К. Маркса «Капитал». Не случайно В.И. Ленин в своих «Философских тетрадях» отмечал, что «если Marx не оставил «Логики» (с большой буквы), то от оставил логику «Капитала», и это следовало бы сугубо использовать по данному вопросу. В «Капитале» применена к одной науке логика, диалектика

* К 200-летию со дня рождения К. Маркса 
и теория познания ... материализма, взявшего все ценное у Гегеля и двинувшее сие ценное вперед» $(4,29$, с. 301). Этому высказыванию В.И. Ленина предшествует следующий, сформулированный им, афоризм: «Нельзя вполне понять «Капитала» К. Маркса и особенно его I главы, не проштудировав и не поняв всей логики Гегеля. Следовательно, никто из марксистов не понял Маркса 1/2 века спустя» $(4,29$, с. 162$)$.

Задумав в этой связи написать специальный труд по диалектике, В.И. Ленин самым тщательным образом проштудировал и законспектировал «Науку логики» и «Лекции по истории философии» Г. Гегеля, работы других мыслителей. При этом В.И. Ленин выделил 19 элементов диалектики и дал ее краткое определение. Она есть «учение о единстве противоположностей. Этим будет схвачено ядро диалектики, но это требует пояснения и развития $(4,29$, с. 203). Но подобно К. Марксу, В.И. Ленину также не удалось завершить свою работу по созданию такого труда.

Необходимо, однако, подчеркнуть, что ленинские размышления и наработки по данному вопросу послужили отправным пунктом исследования диалектики (логики) «Капитала» К. Маркса. Оно нашло отражение в многочисленных статьях и в целом ряде монографий, написанных советскими философами в течение 50-х - 80-х г.г. прошлого века.

Обобщая концептуальные идеи, выдвинутые советскими философами, можно выделить два главных направления этого исследования. В рамках первого из них внимание акцентируется на отличительных особенностях диалектического метода, примененного К. Марксом в «Капитале», способе восхождения от абстрактного к конкретному, присущих ему категорий.

Пальма первенства здесь принадлежит М.М. Розенталю. В 1955 году вышла в свет его монография «Вопросы диалектики в «Капитале» Маркса» (5).Дальнейшее осмысление затронутых в ней вопросов нашло отражение в другой монографии М.М. Розенталя «Диалектика «Капитала» К. Маркса» (6). Как и в предыдущей, во введении к ней дана общая характеристика философского значения «Капитала». По словам автора, «главная же цель книги остается прежней - исследование основных сторон и элементов диалектики «Капитала» в целом. В соответствии с этой целью книга разделена на две части. Первая посвящена преимущественно «объективной», а вторая - «субъективной» диалектике, разумеется, с учетом условности такого деления, поскольку обе эти стороны диалектики неразрывно связаны» $(6$, с. 4$)$.

Сообразно этому первая часть «Диалектика объективного развития и ее воспроизведение в законах и категориях диалектики» состоит из шести глав. В первой из них анализируется диалектическая теория развития (здесь выделяются категории движения, развития); во второй главе - категория закона и принцип историзма; в третьей главе - переход количественных изменений в качественные (здесь выделяются категории качества, количества, меры); в четвертой главе - развитие как процесс возникновения, нарастания и преодоления противоречий (здесь выделяется категория противоречия); в пятой главе - закон отрицания отрицания в «Капитале»; в шестой главе - категория отчуждения в «Капитале», отчуждение и социализм. Соответственно вторая часть «Диалектика движения мысли и ее форм к объективной истине» включает в себя также шесть глав. В первой из них рассматривается логика исследования сущности объекта (здесь выделяются категории видимости, сущности и явления); во второй главе - абстракция, ее сущность и роль в познании; в третьей главе -абстрактное и конкретное. Способ восхождения от абстрактного к конкретному; в четвертой главе - анализ и синтез, индукция и дедукция в процессе воспроизведения конкретной целостности объекта; в пятой главе - историческое и логическое в процессе познания. Логический метод «Капитала»; в шестой главе - логическая система «Капитала» и система диалектической логики. В заключении к данной книге показан революционно-критический характер и партийность метода «Капитала».

Отсюда видно, в ней раскрываются две взаимосвязанные стороны диалектики «Капитала» К. Маркса, выделяются присущие им категории. При этом, однако, не ставится задача систематического и детального отображения самой этой диалектики, следовательно, внутренней логики «Капитала» как целостной системы субординированных категорий и законов.

Напротив, в рамках второго направления была предпринята попытка преодолеть указанный недостаток и тем самым раскрыть диалектику как таковую, диалектическую логику в экономической науке на примере «Капитала». Первый шаг в этом направлении сделан Э.В. Ильенковым в его монографии «Диалек- 
тика абстрактного и конкретного в «Капитале» К. Маркса» (7). В ней весьма подробно анализируются следующие вопросы: диалектическое и метафизическое понимание конкретного; единство абстрактного и конкретного как закон мышления; восхождение от абстрактного к конкретному и его роль в научном познании (в том числе и в развитии политической экономии); соотношение логического развития и конкретного историзма; способ восхождения от абстрактного к конкретному в «Капитале» К. Маркса.

Уделяя особое внимание последнему вопросу, Э.В. Ильенков вполне правомерно утверждает, что именно этот способ позволяет выявить логическую структуру «Капитала». Сопоставив ее с логикой движения мысли Д. Рикардо, автор видит свою задачу «в том, чтобы выделить всеобщие, логические моменты движения мысли Маркса в экономическом материале, логические формы, применимые в силу своей всеобщности и в любой другой теоретической дисциплине» (7, c. 209).

Посредством диалектической интерпретации таких сопряженных общенаучных методов познания, как анализ - синтез и дедукция - индукция, Э.В. Ильенков выделяет стоимость как исходную и вместе с тем всеобщую категорию «Капитала». В действительности же таковой является не стоимость (так считал Д.Рикардо), а товар. Именно этот последний дает возможность (как в логическом, так и в историческом аспектах, которые в данном случае совпадают друг с другом) перейти к рассмотрению денег, капитала и т.д.

Не считая нужным далее углубляться в экономическую логику «Капитала», автор сосредоточил свое внимание на проблеме логического противоречия. При этом оно трактуется в трех различных аспектах: 1) противоречие как условие развития науки; 2) противоречия трудовой теории стоимости и их диалектическое разрешение у Маркса; 3) противоречие как принцип развития теории.

Таким образом, в данной книге вопрос о логической структуре экономических категорий «Капитала» К. Маркса остался открытым. Подчеркнем, этому вопросу посвящены две другие монографии, первая из которых (как, впрочем, и книга Э.В. Ильенкова) была опубликована при поддержке М.М. Розенталя.

В этом случае речь идет о монографии В.Н. Типухина «Метод восхождения от абстракт- ного к конкретному в «Капитале» К. Маркса (8). Она включает в себя три главы. Первая глава посвящена исследованию движения (в логическом аспекте) от элементарной абстракции к сущности; при этом не стоимость, а товар выступает в качестве исходного пункта подобного движения, т.е. восхождения от абстрактного к конкретному; затем - от товара к капиталу. Вторая глава - исследованию сущности конкретного в его многообразии; в ней характеризуется абстрактное выражение капитала, процесса труда и сущности капитала как такового. Третья глава - исследованию воспроизведения конкретного целого, в ней анализируется сущность капитала и форма ее движения, воспроизведение капитала как конкретного целого.

В монографии Л.А. Маньковского «Логические категории в «Капитале» К. Маркса (9) предпринята попытка раскрыть диалектическую логику в экономической науке на примере данного труда. Автор поставил перед собой следующую задачу: разработать систему логических категорий и соответствующих им начал посредством изложения принципов построения системы логических и экономических категорий, содержащихся в «Капитале». В соответствии с этой задачей рассматривается широкий круг вопросов (монография включает в себя 12 глав). В первой главе исследуются принципы построения системы логических и экономических категорий в «Капитале». Во второй главе - первоначальная характеристика предметности (вещи), качество, количество в связи с анализом потребительной стоимости. В третьей главе - категории вещь и отношение, внешнее и внутреннее в связи с анализом меновой стоимости. В четвертой главе - дальнейшее развитие категорий отношения, качества и количества; категория меры; переход от меновой стоимости товара к стоимости; труд как субстанция стоимости. В пятой главе - абстрактный и конкретный труд; мера стоимости; дальнейшее развитие категорий отношение, стоимости и вещи. В шестой главе - дальнейшее развитие формы в связи с дальнейшим развитием категорий отношения и вещи; логический анализ понятия формы стоимости. В седьмой главе - дальнейшее развитие категории меры и ее реализации; двойственный характер труда. В восьмой главе - развитие формы стоимости и реальные меры товаров; категории единичное, особенное, общее. В девятой главе - категории видимости; логический анализ товарного фити- 
шизма и его тайны. В десятой главе - категории реализации в ее связи с категорией действительности; включение практики в процесс познания противоречий и их разрешения в реальном процессе. В одиннадцатой главе - категория движения в связи с анализом метаморфозы товаров и денег как средства обращения товаров; развернутый анализ противоречий и путей их разрешения. В двенадцатой главе - деньги как мера стоимости; дальнейшее развитие категории видимости - проблема реального и идеального, название, символы и знаки.

Таково краткое содержание этих двух монографий, в которых дан логический анализ двух отделов первого тома «Капитала». Однако вопрос о целостном воспроизведении и изложении диалектики (логики) последнего остался нерешенным.

Пожалуй, наиболее важный вклад в решение данноговопроса внес В.А. Вазюлин. В 1968 году вышла в свет его монография «Логика «Капитала» К. Маркса» (при содействии М.М. Розенталя). (10) Причем ее публикация осталась, по существу, незамеченной в научной среде (в сравнении, например, с монографией Э.В. Ильенкова). Между тем, в отличие от вышеуказанных монографий, в которых затрагиваются отдельные аспекты диалектики (логики) «Капитала» К. Маркса, в ней впервые не на словах, а на деле предложено решение весьма актуальной и трудной задачи, за которую ни до, ни после автора никто всерьез не брался. Суть ее он сформулировал следующим образом: «представить объективную логику «Капитала» в сравнении с объективной логикой Гегеля как систему субординированных, внутренне связанных категорий путем выявления их из детального рассмотрения экономического материала «Капитала», взятого в его квинтэссенции, а не в качестве суммы примеров. Автор пытается, во-первых, рассмотреть «механизм» объективной диалектической логики, как он может быть выведен из исследования логики «Капитала»; во-вторых, дать обобщенное понимание логики «Капитала», основанное на подробном изучении этого произведения. Эта логика и будет, на наш взгляд, объективной диалектической логикой вообще, развитой из ее внутренних связей. Другими словами, такая логика есть изображение систематического мышления о диалектическом объекте. (10, с. 26) Заметим, это рассмотрение позволило автору показать, как соответствие объективной логики «Капитала» гегелевской объективной логике, так и превосходство первой над последней.

К числу несомненных заслуг В.А. Вазюлина следует отнести,

во-первых, самый подход к решению указанной проблемы, поставленной еще В.И. Лениным, суть которого заключается в необходимости материалистического переосмысления «Науки логики» Г. Гегеля.

Во-вторых, выделение в системе логики «Капитала» объективной и субъективной логики. Под первой понимается отражение в мышлении развивающегося объекта, а под второй - как происходит отражение в мышлении развивающегося объекта. Иными словами, предмет объективной логики - мышление, взятое с точки зрения того, что в нем отражается, а предмет субъективной логики - мышление, взятое с точки зрения того, как, каким образом отражается изучаемый объект. Следовательно, в обоих случаях предметом является мышление, но в первом случае рассматривается содержание мышления, а во втором - форма мышления.

$B$-третьих, четкое и лаконичное определение исходной абстракции диалектического восхождения как метода построения системы логических категорий «Капитала». Это определение характеризуется следующими положениями.

1. В исходной абстракции отражается такое отношение развивающегося предмета, которое дальше разложить нельзя, не выходя за рамки данного предмета.

2. В исходной абстракции воспроизводится простейшее отношение в сравнении с другими отношениями изучаемого предмета.

3. Исходная категория отражает зародышевое противоречие, на основе которого и из которого вырастают все другие отношения данного предмета.

4. Исходная абстракция воссоздает исторически первичное отношение развивающегося предмета.

5. Исходная абстракция отображает простейшее отношение изучаемого предмета и, следовательно, некоторую совокупность различных многообразных сторон последнего.

B-четвертых, выделение отличительных особенностей двух методов познания: восхождения от конкретного к абстрактному и от абстрактного к конкретному. При этом, в отличие от общепринятой точки зрения, автор рассматривает последнее восхождение как процесс 
движения от непосредственного знания к сущности самой по себе и от сущности как таковой к явлению и действительности.

$B$-nятых, определение основных типов совпадения логического и исторического в «Капитале» (по мнению автора, в этом произведении можно выделить шесть таких типов).

B-шестых, выделение двух взаимосвязанных витков спирали, присущих диалектическому восхождению от абстрактного к конкретному в «Капитале». Один из них - большой виток, который охватывает три тома данного труда. В свою очередь начальный отрезок большого витка спирали представляет собой малый виток спирали того же типа. Он образует первый отдел «Капитала».

Отмечая эти заслуги В.А. Вазюлина, следует вместе с тем выделить главный недостаток его монографии. Этот недостаток заключается в том, что ее автор излагает логику «Капитала» в терминах «Науки логики» Г. Гегеля, многие из которых обусловлены идеалистической методологией последней. Поэтому здесь нужно иметь в виду указание В.И.Ленина: «Логику Гегеля нельзя применять в данном ее виде, нельзя брать как данное. Из нее надо выбрать логические (гносеологические) оттенки, очистив от Ideenmystik (мистики идей.- Н.С.); это еще большая работа» (4, 29, с. 238). Правда, справедливости ради, надо отметить, что В.А. Вазюлин не ставил перед собой такой задачи. Она еще ждет своих исследователей.

В связи с вышеизложенным возникает общеметодологический вопрос: почему советским философам так и не удалось решить поставленную проблему, связанную с сознанием систематического труда по диалектике (логике) «Капитала» К. Маркса? На наш взгляд, здесь можно выделить две основные причины. Во-первых, рассматривая «Науку логики» Г. Гегеля, они ограничились преимущественно, говоря словами К. Маркса, «делом логики» в противоположность «логике дела». В таком аспекте выделялись ее ключевые положения, которые подвергались энергичной критике с материалистических позиций. Конечно, такая критика была вполне правомерна. Но при этом почему-то забывали о главном, а именно, о необходимости выявления того «рационального зерна», которое имманентно логике Г. Гегеля (на что прежде всего обращали внимание и К. Маркс, и Ф.Энгельс, и В.И. Ленин) и которое подлежит теоре- тико-методологическому переосмыслению для выработки подлинно научной диалектики (логики) как системы субординированных категорий и законов. Во-вторых, непонимание сути экономической логики «Капитала» К. Маркса и стремление раскрыть ее в духе категорий гегелевской логики.

Приведем лишь два примера. Первый: почти весь основной текст монографии В.А. Вазюлина посвящен первому тому «Капитала». Что же касается второго тома последнего, то полагая, что он не был завершен К. Марксом (как, впрочем, и третий том), автор рассматривает его содержание (в логическом аспекте) лишь в рамках трех параграфов: 1) существование (кругооборот капитала); 2) явление (оборот капитала); 3) существенное отношение (воспроизводство и обращение всего общественного капитала). Как видим, В.А. Вазюлин пытается «втиснуть» весь экономический материал этого тома в три категории гегелевской логики. Между тем здесь нужно использовать другие категории, коmорых в ней нет. Поэтому автор ограничился скромным анализом второго тома «Капитала», посвятив ему лишь 15 страниц. То же самое касается и третьего тома этого труда, содержание которого излагается (в логическом аспекте) как действительность предмета (причем всего лишь на 4 страницах).

Второй пример: заимствуя у В.А. Вазюлина положение о малом витке диалектического восхождения от абстрактного к конкретному (не называя при этом ее автора), Л.А. Маньковский считает, что первый отдел первого тома «Капитала», т.е. «товар и деньги» выступают в качестве непосредственного бытия капитала. Если автор вникнул бы в экономическую логику этого отдела, то он понял бы, что именно товар есть непосредственное бытие капитала, а деньги суть опосредованное бытие последнего. Поэтому не только товар, но и деньги нуждаются в особом логико-теоретическом осмыслении. Кроме того, содержание второго тома «Капитала» (в логическом аспекте) автор определяет посредством лишь одной категории - явление. И тем более нельзя согласиться со следующей трактовкой автора: третий отдел данного тома есть «действительность как единство сущности и явления, их взаимопроникновение», а третий том «Капитала» - это «та же действительность в ее самой зрелой форме, с ясно выраженными в ней возможностями ее отрицания более высоким обще- 
ственным строем» $(11$, с. 360). Вот такая весьма своеобразная «логика» получается, которая свидетельствует о полном непонимании автором экономической логики второго и третьего томов «Капитала» К. Маркса.

Что же касается советских политэкономов, то, разумеется, никто из них не ставил перед собой вышеуказанную задачу. Тем не менее обращают на себя внимание Комментарии к этим томам, написанные Д.И. Розенбергом еще в начале 30-х годов и переиздававшиеся в 60-е - 80-е г.г. прошлого века. (12) Главная ценность этих комментариев (в интересующем нас аспекте) заключается в том, что их автор стремился изложить экономическую логику «Капитала» с точки зрения метода восхождения от абстрактного к конкретному.

Но в целом, однако, рассматриваемая проблема до сих пор остается нерешенной. Имея в виду это обстоятельство, В.Г. Голобоков пишет: «... Проблема метода «Капитала» была одной из центральных не только среди философов, но и среди экономистов. Философы абстрактно и многословно рассуждали на тему, как ее решить и как много дает это решение науке и практике; экономисты были куда активнее и, на первый взгляд, практичнее, так сказать, ближе к жизни. Не дожидаясь, когда философы, перестав летать в облаках отвлеченных рассуждений, возьмут и вычленят логическую структуру «Капитала» в ее диалектической целостности, экономисты стали непосредственно искать исходное звено, за которое взявшись, можно было бы вытянуть всю категориальную цепь, отражающую советскую экономику. То и дело появлялись статьи, книги, монографии, в которых отыскивались «клеточки» и «простейшие отношения» социалистического производства, чтобы затем из них вывести всю теоретическую систему нового общественного строя, как Маркс в «Капитале» все выводил из товара. Но, несмотря на титанизм прилагаемых усилий, результаты неизменно оказывались нулевыми» (13, с. 3-4).

Именно об этом свидетельствуют упорные, действительно титанические усилия, связанные с применением подобного метода к исследованию экономической системы социализма, что вызвало бурную дискуссию. Она развернулась прежде всего по поводу определения исходной категории («клеточки») этой системы. В качестве таковой представители «Школы Цаголова» (кафедра политической экономии экономи- ческого факультета МГУ им. М.В. Ломоносова) предложили планомерность, или планомерную организацию социалистического производства (Н.А. Цагалов, Н.В. Хессин, В.Н. Черковец, С.С. Дзарасов и др.). Наряду с ней были выдвинуты и другие, отличные друг от друга, многочисленные категории (заметим, более трех десятков). Назовем лишь некоторые из них: коллективность, или отношения коллективности (И.И. Кузьминов, А.А. Глухов, З.К. Кирьянова, В.П. Ратников), общественная полезность (Н.П. Федоренко), непосредственно-общественный труд (Ю.В. Пахомов), непосредственно-общественная форма труда (А.К.Покрытан), социалистическое обобществление производства (А.М. Еремин), процесс социалистического обобществления труда (Л.И.Абалкин), социалистический продукт (В.А. Бадер), необходимый продукт (А.Г. Назаров), совокупный общественный продукт, или его общественная форма (В.М. Агеев, А.М. Ковалев, А.И. Ноткин), непосредственно-общественный продукт (А.И. Кащенко) и т.п.

На наш взгляд, такое разнообразие в трактовке этого вопроса объясняется главным образом тремя обстоятельствами.

Во-первых, методологическое осмысление исходной категории социализма нуждается в более основательном обосновании, которое, по меньшей мере, должно соответствовать экономической логике «Капитала». Именно в рамках этой логики следует анализировать структуру социалистической экономики.

Во-вторых, и это, пожалуй, главное: невозможно выделить такую категорию, если сам социализм находится еще в стадии формирования (заметим, концепцию «развитого социализма» нельзя принимать во внимание, поскольку она не соответствовала действительности). В силу этих обстоятельств вышеуказанная дискуссия оказалась незавершенной, а в начале 90-х годов, когда «развитой социализм» потерпел крах и канул в инобытие, надобность в ней уже отпала.

В-третьих, решение рассматриваемой проблемы в современных условиях осложняется еще и тем обстоятельством, что российская политическая экономия (как, впрочем, и российское обществоведение в целом) оказалась в состоянии глубокого системного кризиса. Как известно, последний явился следствием коренных преобразований, развернувшихся в нашей стране с начала 90-х годов прошлого века. По 
своему содержанию они затронули все сферы общественной жизни (экономическую, социальную, политическую и духовную) и в конечном счете сопрягались с существенным изменением главного вектора развития российского общества, ориентированного в новых условиях на построение либерально-рыночной модели капиталистического типа. На волне этих преобразований началось радикальное переосмысление выработанных в течение ряда десятилетий теоретических представлений о предмете и методе фундаментальной экономической науки (таковой является политическая экономия), приведшее к кардинальной смене ее парадигмы. В качестве такой парадигмы была принят западная экономическая теория. (Экономикс).

В соответствии с ней, руководствуясь отнюдь не научно-теоретическими, а политико-идеологическими соображениями, чиновники от науки вкупе с «учеными приказчиками» властей предержащих негласно в «лихие 90-е» приняли решение о ликвидации политической экономии как общетеоретической дисциплины. В итоге политическая экономия оказалась упраздненной из учебного процесса. Вместо этой науки в российских высших и средних учебных заведениях были введены нейтральные в социально-политическом отношении общеобразовательные дисциплины рыночного толка - «экономическая теория», «экономика», «рыночная экономика» и т.п., в которых излагаются основные концептуальные идеи англо-американских курсов Экономикс. Последняя ориентирована главным образом на простое описание (посредством обширного математического инструментария) рыночных процессов, совершающихся на уровне микро- и макроэкономики. В результате экономическая теория, по существу, заменяется чистой математикой.

Не удивительно поэтому, что многие российские экономисты не скрывают своего негативного отношения к различного рода курсам Экономикс. Подобно зарубежным экономистам (прежде всего институционального и посткейнсианского направлений) они также подвергают эти курсы резкой критике, полагая, что им присущи такие методологические атрибуты, как априорность, абстрактность, эмпиризм, схоластика, «математическое шарлатанство» и т.п., что эти атрибуты не имеют ничего общего с реальной экономикой.

В связи с этим была предпринята попыт- ка, связанная с предложением необходимости восстановления научного статуса политической экономии как учебной дисциплины (здесь имеется в виду письмо, подготовленное и направленное группой ученых в 2002 году тогдашнему министру образования РФ). Но, увы, эта попытка не увенчалась успехом: как говорится «воз и ныне там». По-видимому, нужно еще время для того, чтобы такая необходимость была в полной мере осознана чиновниками от науки (разумеется, вкупе с «учеными приказчиками» властей предержащих).

В этой связи нужно, однако, отметить одно весьма важное обстоятельство: в конце XX - начале XXI в.в. интерес к политической экономии как общетеоретической дисциплине существенно возрос не только в зарубежных странах, но и в нашей стране. Так, вопреки государственным стандартам, установленным Министерством образования и науки РФ, в 1990 г.г. активизировалась работа, связанная с созданием нового курса политической экономии. В результате появилась обширная литература (учебного, монографического и публицистического характера), в которой излагаются современные представления об этой науке.

Поясним: общеизвестно, что научный статус политической экономии определяется прежде всего тем, что она дает целостное, систематическое представление об условиях и формах экономической деятельности людей на различных ступенях развития общества. Суть политико-экономического подхода состоит в том, чтобы рассматривать все экономические явления и процессы с точки зрения: а) причин возникновения; б) всесторонней взаимосвязи; в) законов развития; г) условий отмирания. Иными словами, эти явления и процессы рассматриваются здесь с точки зрения диалектического метода.

Отсюда проистекает специфика предмета политической экономии. Будучи общетеоретической или экономическо-философской наукой (не случайно ее раньше называли философией хозяйства), она изучает экономику как фундаментальную сферу общественной жизни, раскрывает законы ее развития, выявляет корни социальных противоречий и показывает пути их разрешения. В центре ее внимания находятся производственные отношения, в рамках и посредством которых осуществляется развитие производственных сил, трудовое взаимодействие людей с природой. При этом внимание 
акцентируется на том, что производственные отношения всегда функционируют в своей социальной оболочке, т.е. как отношения собственности. Поскольку последние охватывают всю совокупность производственных отношений, то в конечном счете именно они определяют отличительные черты той или иной экономической системы, направления ее трансформации. Следовательно, политическая экономия изучает особенности и законы развития разных типов экономических систем, их закономерную смену в ходе естественноисторического процесса. Она призвана и стремится дать многообразное видение сущности этого процесса, внести весомый вклад в разработку общей теории социального развития на основе обобщения передовых достижений различных отраслей знаний экономических наук и хозяйственной практики.

В этом качестве политическая экономия выступает, во-первых, как основа социальной философии, т.е. она изучает диалектику экономики как саморазвивающейся фундаментальной сферы общества, выявляет ключевую роль материального производства в общественной жизни, раскрывает диалектическую взаимосвязь производительных сил и производственных отношений в системе способа производства, структуру и законы движения экономической системы, зависимость надстроечных форм (социальных, политических, правовых, духовных и т.п.) от экономического базиса, а также особенности и направления воздействия этих форм на развитие данного базиса (в рамках ее предмета).

Во-вторых, как основа философии истории, т.е. она изучает диалектику историко-экономического процесса, присущие ему спец- ифические, особые и общие закономерности возникновения, становления и развития разных типов экономических систем, причины и механизмы перехода от одной экономической системы к другой, главное направление социальной трансформации этих систем в контексте общественного прогресса.

В этой связи возникает необходимость создания систематического труда по диалектике (логике) «Капитала» К. Маркса, имеющего ключевое значение для развития не только философии, но и политической экономии как общетеоретической экономической науки (14, с. 221-228). Оно предполагает, во-первых, материалистическое переосмысление «рационального зерна» гегелевской логики, очищение ее от идеалистической мистики, выделение присущих ей тех логических категорий, которые действительно являются ступенями научного познания; во-вторых, использование уже известных и введение новых логических категорий, что позволяет отобразить логику «Капитала» на всех структурных уровнях этого произведения; в-третьих, изложение логической структуры «Капитала» в соответствии с его экономической логикой; в-четвертых, выявление диалектики общего и особенного в логическом методе «Капитала», что служит исходным пунктом осмысления сути диалектической логики вообще. Разумеется, создание подобного труда является довольно сложной, но вместе с тем весьма важной задачей наших обществоведов, которое должно осуществляться на основе синтеза двух наук - философии и политической экономии. В этом - залог успеха решения данной задачи.

\section{Библиографический список}

1. Маркс К., Энгельс Ф. Соч. Т. 13.

2. Маркс К., Энгельс Ф. Соч. Т. 29.

3. Маркс К., Энгельс Ф. Соч. Т. 32.

4. Ленин В.И. Полн. Собр. Соч. Т. 29.

5. Розенталь М.М. Вопросы диалектики в «Капитале» Маркса. Москва. 1955.

6. Розенталь М.М. Диалектика «Капитала» К. Маркса. Москва. 1967.

7. Ильенков Э.В. Диалектика абстрактного и конкретного в «Капитале» К. Маркса. Москва. 1960.

8. Типухин В.Н. Метод восхождения от абстрактного к конкретному в «Капитале» К. Маркса //Труды Омского с-х. ин-та им. С.М. Кирова, 1961. Т. 45.

9. Маньковский Л.А. Логические категории в «Капитале» К. Маркса //Учен. зап. Моск. гос. пед. ин-та им. В.И. Ленина, 1962. № 179.

10. Вазюлин В.А. Логика «Капитала» К. Маркса. Москва. 1968.

11. История марксистской диалектики. От возникновения марксизма до ленинского этапа. //Отв. ред. М. М. Розенталь. Москва. 1971. 
12. Розенберг Д.И. Комментарии к первому тому «Капитала» К. Маркса; он же. Комментарии ко второму и третьему томам «Капитала» К. Маркса. Москва. 1961.

13. Затянувшаяся сенсация (вместо предисловия) //Вазюлин В.А. Логика «Капитала» К. Маркса. Москва. 2002.

14. Сычев Н.В. Актуальные проблемы политической экономии. Москва. 2015. с. 221-228.

Поступила в редакцию 31.08.2018 